Canadian

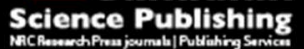

Canadian Journal of Civil Engineering Revue canadienne de génie civil

\title{
Seismic Design and Response of Steel Multi-Tiered Concentrically Braced Frames in Canada
}

\begin{tabular}{|r|l|}
\hline Journal: & Canadian Journal of Civil Engineering \\
\hline Manuscript ID & cjce-2015-0399.R2 \\
\hline Danuscript Type: & Article \\
\hline Complete List of Authors: & $\begin{array}{l}\text { Imanpour, Ali; Polytechnique Montreal, Civil, Geological and Mining } \\
\text { Engineering } \\
\text { Tremblay, Robert; École Polytechnique, Dép. de génie civil }\end{array}$ \\
\hline Keyword: & $\begin{array}{l}\text { Multi-tiered concentrically braced frames, Seismic response, Nonlinear } \\
\text { analysis }\end{array}$ \\
\hline \multicolumn{2}{|c}{} \\
\hline
\end{tabular}




\section{Seismic Design and Response of Steel Multi-Tiered Concentrically}

\section{Braced Frames in Canada}

Ali Imanpour ${ }^{1}$ and Robert Tremblay ${ }^{2}$

${ }^{1}$ Ph.D. Candidate, Dept. of Civil, Geological and Mining Engineering, Polytechnique Montreal, Montreal, QC, Canada H3C 3A7.

${ }^{2}$ Professor, Dept. of Civil, Geological and Mining Engineering, Polytechnique Montreal, Montreal, QC, Canada H3C 3A7.

Correspondence:

Name: Ali Imanpour

Address: 2900, boul. Édouard-Montpetit Université de Montréal Campus, 2500, Chemin de Polytechnique, Montréal, Québec, H3T 1J4

Telephone number: 514-340-4711, local 3720.

E-mail address: aimanpour@gmail.com 


\begin{abstract}
This article investigates the seismic design and response of steel multi-tiered concentrically braced frames (MT-BFs) in which braces meet at columns between diaphragms. The seismic design provisions of CSA S16-14 are described and illustrated for 3-tiered Type MD (moderately ductile) and 5-tiered Type LD (limited ductile) braced frames. Analysis methods are proposed to evaluate the in-plane flexural demand on columns. The seismic response of the frames is examined through nonlinear response history analysis. As assumed in design, inelastic deformations tend to concentrate in one tier over the frame height, causing non-uniform drift demands and in-plane bending moments in the columns. CSA S16 provisions predicted well the frame in-plane flexural response and result in acceptable ductility demands on the braces. An extended seismic analysis and design approach that accounts for vertical distribution of brace tension yielding along the frame height is proposed for frames that exceed the limits prescribed in CSA S16.
\end{abstract}

Key words: Multi-tiered concentrically braced frames, Seismic response, Nonlinear analysis. 


\section{Introduction}

Steel multi-tiered braced frames (MT-BFs) are braced frames that comprise two or more bracing panels stacked on top of each other between horizontal diaphragms in a building. This geometry is common in tall single-storey buildings such as industrial facilities, sport centers, airplane hangars or warehouses. An example is shown in Fig. 1a. X-, V, Inverted V, and diagonal bracing configurations can be utilized in MT-BFs. Multi-tiered braced frames represent an economical and practical option for such buildings as they use shorter braces that are more effective in compression and more easily satisfy slenderness limits compared to braces that span over the full frame or storey height. For very tall applications, single diagonal members become impractical and a multi-tiered configuration often represents the only available solution. In seismic design, smaller braces typically lead to reduced seismic force demands on brace connections, columns, and other structural components. In MT-BFs, the columns are braced at every brace to column connection in the plane of the frame while buckling out-of-plane can occur over the full frame or storey height. Therefore, I-shaped members oriented such that strong axis bending occurs out-ofplane are generally used for the columns. This arrangement is also suitable for MT-BFs located on exterior walls where the columns must resist lateral wind loads applied to the wall cladding. Adjacent gravity columns located in the exterior wall of the building can similarly be laterally braced by adding horizontal struts at the tier levels (Imanpour et al. 2016a).

Compared to braced frames with braces spanning over the entire storey height, MT-BFs exhibit a more complex inelastic seismic response that may lead to undesirable failure modes. In MT-BFs, brace buckling produces inwards unbalanced horizontal loads that are imposed to the columns. Horizontal struts placed between tiers (Fig. 1b) are needed to resist these forces and mitigate inplane flexural demands on the columns. However, even if struts are provided, studies show that 
inelastic deformations tend to concentrate in the bracing members of one tier along the frame height (Imanpour et al. 2012a, 2012b), which also induces in-plane bending moments in columns that must be explicitly accounted for in design to prevent column failure (Fig. 1c) under combined axial compression and bending moment (Imanpour et al. 2016b). In addition, nonuniform drift distribution may impose excessive ductility demand on the inelastic braces and cause premature brace failure (Fig. 1c). Finally, brace out-of-plane buckling may affect out-ofplane stability of the columns as shown in Fig. 1d. These last two issues must also be addressed in design to achieve a satisfactory seismic response. The commentary to CSA S16-01 (CISC 2001) warned design engineers against the detrimental effects of unbalanced brace loads on columns and the possibility of drift concentration in MT-BFs. In 2009, special design provisions have been introduced in CSA S16 (CSA 2009) to mitigate these effects and achieve satisfactory MT-BF seismic response. These provisions were revisited in the 2014 edition of S16 to reflect recent research findings. This paper describes these seismic provisions and their application is illustrated for X-braced frame examples. Two simple analysis methods are proposed to obtain column force demands and tier drifts. The response of typical frames having different numbers of tiers and tier height ratios is examined through nonlinear response history analysis. An extended analysis and design approach is then proposed to determine in-plane seismic demand in frames having a large number of tiers for which brace tension yielding is expected to develop in more than one tier.

\section{CSA S16 Seismic Design Provisions for MT-BFs}

The National Building Code of Canada (NRCC 2015) defines two categories of concentrically braced steel frames that must be designed and detailed to withstand earthquake effects through 
stable inelastic deformations: moderately ductile (Type MD) and limited ductility (Type LD) braced frames with ductility-related force modification factors $R_{\mathrm{d}}$ equal to 3.0 and 2.0, respectively. Seismic requirements for both systems are given in Clause 27 of CSA S16 design standard for steel structures (CSA 2014). For both categories, the bracing members are designed and detailed to dissipate seismic energy by yielding in braces. Other components must resist gravity load effects plus seismic induced forces corresponding to the brace probable resistances. Two loading cases must be considered: one where the compression braces attain their probable compressive (buckling) resistance $C_{\mathrm{u}}$ and one where they reach their degraded buckled (postbuckling) resistance $C^{\prime}{ }_{\mathrm{u}}$; in both cases, the tension braces carry forces equal to their probable yield tensile resistances $T_{\mathrm{u}}$ (Fig. 2). The first case reflects a situation likely to occur early during an earthquake, when the tension braces reach their yield strength after the compression braces have just buckled. The second case occurs after the frame has sustained several reversed inelastic cyclic loading. The two loading cases aimed at bounding intermediate conditions that are expected during an earthquake.

In MT-BFs, braces meet at columns between horizontal diaphragms and additional requirements must be met to ensure satisfactory seismic response. As shown in Fig. 2a, unbalanced horizontal loads are imposed to columns after buckling of the braces, when the compressive strength of the braces reduces to $C^{\prime}{ }_{\mathrm{u}}$ and larger tension develops in the tension-acting braces. This imposes high in-plane flexural demand on the columns which may compromise frame stability (Fig. 1b), similar to the response of K-bracing, a configuration prohibited for Types MD and LD CBFs. In MT-BFs, this undesirable behaviour is mitigated by introducing horizontal struts between braced tiers that can resist the expected unbalanced brace loads. After brace buckling, lateral seismic loads are entirely resisted up to full yielding of the tension braces by the truss mechanism formed 
by the braces, struts and columns, rather than by flexure of the columns.

Even if struts are present, brace tension yielding in MT-BFs tends to initiate and concentrate in a critical tier where the braces offer the lowest storey shear resistance. Plastic elongation of the braces in this critical tier results in relatively larger tier drifts, which induces in-plane flexural demand on the columns (Fig. 1c). This behaviour is expected in all MT-BFs, even if the bracing panels and braces are well proportioned to achieve uniform storey shear resistance over the frame height because of unavoidable variations in material properties, cross-sectional area, geometrical imperfections or boundary conditions that exits between tiers of as-built MT-BFs. The columns must therefore resist the axial compression combined with the bending moments induced by the non-uniform drift pattern. Concentration of inelastic deformations in the critical tier can also impose excessive ductility demand on the bracing members in that tier which, in turn, can cause premature failure of the braces (Fig. 1c).

Special seismic provisions for MT-BFs have been introduced for the first time in the 2009 edition of CSA S16 (CSA 2009). Struts are required between tiers and the columns must be designed for the combined axial load and bending moment induced assuming that brace tension yielding only develops in the critical tier. All possible critical tier scenarios must be examined considering possible variability in brace strength. To limit tier drifts and brace ductility demand, MT-BFs in CSA S16-09 were only permitted for Type LD CBFs. Additionally, concomitant notional out-of-plane transverse loads were specified at brace-to-column intersecting points equal to $10 \%$ of the axial load carried by the compression members meeting at these points. These loads aimed at providing the columns with sufficient strength to resist out-of-plane forces due to initial geometric imperfections and brace out-of-plane buckling.

MT-BFs having up to 5 tiers and designed in accordance with CSA S16-09 as Type MD were 
investigated to examine the possibility of relaxing S16 seismic provisions (Imanpour et al. 2012b; Imanpour and Tremblay 2014a). The studies confirmed that in-plane flexural demand induced on MT-BF columns can be well predicted by the S16 requirements. Non-uniform distribution of drift between tiers and column flexural demands were found to generally increase when increasing the number of tiers and the $R_{\mathrm{d}}$ factor. Although more severe, the seismic response of some of the Type MD frames was found acceptable. The studies finally showed that MT-BF columns experienced out-of-plane bending moments corresponding to that induced by notional loads equal to $0.4-0.8 \%$ of the compression axial forces in the columns at brace intersecting points, significantly lower than the $10 \%$ transverse notional load specified in CSA S16-09. In 2014, MT-BF provisions were modified to reflect these recent findings: MT-BFs are permitted to be used for Type MD braced frames with 2 or 3 tiers and for Type LD braced frames up to 5 tiers. The notional out-of-plane load has been reduced to $2 \%$ of the column axial compression load below the brace-to-column intersecting point.

\section{Seismic Design of MT-BFs}

\section{Prototype Building and Design Data}

A single-storey industrial building with $102 \mathrm{~m} \mathrm{x} 48 \mathrm{~m}$ plan dimensions is selected for this study. The building height, $h_{\mathrm{n}}$, is $20 \mathrm{~m}$ and the spacing of the exterior columns, $L$, is $6 \mathrm{~m}$. Lateral loads in each direction are resisted by four MT-BFs, two frames per exterior wall. The building is located on a class C site in Vancouver, BC. Three braced frames are examined in this study (Fig. 3). The design of the 3-tiered Type MD frame of Fig. 3a is examined first. The design of the two other frames is discussed later. The design earthquake loads were determined in accordance with NBCC 2015. The importance factor, $I_{\mathrm{E}}$ is equal to 1.0 and the factors $R_{\mathrm{d}}$ and $R_{\mathrm{o}}$ are 3.0 and 1.3 
respectively. The building period is equal to $1.0 \mathrm{~s}$, resulting in a design spectral acceleration $(S)$ of $0.42 \mathrm{~g}$. Using the equivalent static force procedure and accounting for accidental torsion, the storey shear per braced frame, $V$, is $389 \mathrm{kN}$ including $14 \mathrm{kN}$ notional load. The design roof dead load (D) and snow load (S) are equal to 1.2 and $1.64 \mathrm{kPa}$, respectively. The gravity induced column axial load is equal $P_{\mathrm{G}}=232 \mathrm{kN}$ for the load combination $\mathrm{D}+\mathrm{E}+0.25 \mathrm{~S}$. For this structure, the stability coefficient is less than 0.1 and P-delta effects are ignored.

\section{Design of the Braces}

The braces in each tier are designed to resist in tension and compression the seismic storey shear, $V$. The resulting brace axial compression forces due to seismic and gravity loads are equal to 395 $\mathrm{kN}$ in Tier 1 and $259 \mathrm{kN}$ in Tiers 2 and 3. The braces are designed for out-of-plane buckling in compression, assuming an effective length factor $K=0.45$ for this $\mathrm{X}$-bracing configuration. The braces were selected from ASTM A500, grade $\mathrm{C},\left(F_{\mathrm{y}}=345 \mathrm{MPa}\right)$ square HSS members satisfying CSA S16-14 brace slenderness and width-to-thickness ratios limit. The selected braces are shown in Fig. $3 \mathrm{a}$ and their properties are given in Table 1. In the table, $C_{f}$ and $C_{r}$ are the brace factored compression loads and axial resistances, respectively. The probable brace tensile and compressive resistances determined with probable steel yield strength $R_{\mathrm{y}} F_{\mathrm{y}}$ of $460 \mathrm{MPa}$ are also given.

\section{Design of the Struts}

As required in CSA S16-14, horizontal struts are provided between the tiers. The most critical brace force condition for the struts is the second case of Fig. 2a as shown in Fig. 4a. A W200x52 is selected to resist maximum axial compression of $649 \mathrm{kN}$ at Tier 1 . For uniformity, the same section is also used for the strut at Tier 2.

As discussed in the next section, the critical tier for this frame is Tier 1. If brace inelastic 
response is constrained to that tier, the loading condition of Fig. 4a would not occur as the compression brace forces in Tiers 2 and 3 would remain equal to, or close to $C_{\mathrm{u}}=479 \mathrm{kN}$ instead of $C^{\prime}{ }_{\mathrm{u}}=200 \mathrm{kN}$. This would result in a reduced axial compression of $439 \mathrm{kN}$ in the strut at Tier 1. For this frame, however, the difference in storey shear resistances between tiers is small (less than $5 \%$ as discussed in the next section) and it is possible that the critical tier actually forms in Tier 2 or 3 due to variability in brace resistances along the frame height, which would result in strut compression forces equal to those obtained when considering $C^{\prime}{ }_{\mathrm{u}}$ in all tiers. For frames with nearly uniform storey shears, it is therefore advisable to consider the loading condition of Fig. 4a for strut design.

\section{Design of the Columns}

The building exterior columns are $\mathrm{W}$ shaped members continuous over the full frame height and oriented such that out-of-plane bending occurs about their strong axis. They are assumed pinned at their top and bottom ends for bending about both directions. The columns are first designed to resist the gravity loads plus the brace axial loads of the first brace force scenario of Fig. 2a, as illustrated in Fig. 4b. At brace buckling, the drifts are still small and bending moments in the columns can be ignored. The column segment in Tier 1 governs the design because it has the largest buckling length in the plane of the frame $(10 \mathrm{~m})$ and carries the highest axial compression $(3460 \mathrm{kN})$. The column buckling length about strong axis is taken equal to $20 \mathrm{~m}$. A W760x257 section is selected.

The column must then be verified for the additional loading condition for MT-BFs which accounts for a possible concentration of brace inelastic deformations in the critical tier. For this purpose, the critical tier is identified by comparing the horizontal storey shear resistances $V_{\mathrm{u}}$ provided by the braces when they develop their probable resistances $T_{\mathrm{u}}$ and $C_{\mathrm{u}}$ (Imanpour et al. 
2012b). As shown in Table 1, Tier 1 is the weakest tier where brace tension yielding is expected to develop and cause inelastic tier drifts and degradation of the brace compressive strength from $C_{\mathrm{u}}$ to $C^{\prime}{ }_{\mathrm{u}}$. The storey shear resisted by the braces in Tier 1 will therefore reduce from $V_{\mathrm{u}}$ to $V_{\mathrm{u}}$ in Table 1 , as determined with brace forces $T_{\mathrm{u}}$ and $C^{\prime}{ }_{\mathrm{u}}$ in that tier. This will diminish the force demand in the tension braces in the stronger Tiers 2 and 3, preventing brace tension yielding in these tiers, and subsequent frame inelastic deformations will therefore concentrate in Tier 1 . The frame deformed shape and brace axial forces for this scenario are shown in Fig. 4c. As specified in CSA S16, member forces and deformations are determined when the roof displacement reaches the anticipated deflection including inelastic effects, i.e. $\delta_{\text {roof }}=R_{\mathrm{d}} R_{\mathrm{o}} \delta_{\mathrm{e}} / I_{\mathrm{E}}$, where $\delta_{\mathrm{e}}$ is the elastic roof lateral deflection under the design seismic force. For this frame, $\delta_{\mathrm{e}}$ is $32 \mathrm{~mm}$ and $\delta_{\text {roof }}=125 \mathrm{~mm}$.

Column forces at this target displacement can be obtained from a nonlinear incremental static (pushover) analysis. This however requires explicit modelling of the inelastic response of the braces in tension and compression, including brace buckling and subsequent degradation of the compression strength under cyclic loading (Imanpour and Tremblay 2014b). Such models often cause convergence difficulties and are not readily available in commercially available structural analysis programs. For MT-BF design, two simpler methods are proposed herein to obtain design column forces. The first one uses static analysis technique available in structural analysis software. The second one uses classical three moment equation which can be easily implemented in design spreadsheets.

In the static analysis technique, the anticipated roof drift is imposed to the braced frame structural model in which the bracing members that have reached their probable resistances are removed and replaced by axial forces corresponding to their probable resistances. Design column 
axial forces and bending moments are directly obtained from this analysis. This technique is illustrated in Fig. 4c. Braces in the critical Tier 1 are replaced by forces $T_{\mathrm{u}}=1559 \mathrm{kN}$ and $C^{\prime}{ }_{\mathrm{u}}=$ $312 \mathrm{kN}$. In Tiers 2 and 3, the compression braces are replaced by forces $C_{\mathrm{u}}=479 \mathrm{kN}$. Truss elements are kept in the model for the tension braces in Tiers 2 and 3 as these members are still elastic. Static analysis is performed by imposing the gravity loads plus a horizontal displacement of $125 \mathrm{~mm}$ at the roof level. In Fig. 4c, brace tension loads in Tiers 2 and 3 are obtained from this analysis, as well as in-plane shears and bending moments in the columns. As anticipated, tension brace loads of 790 and 777 in Tiers 2 and 3 are smaller than $T_{\mathrm{u}}=998 \mathrm{kN}$. The analysis gives factored axial compression $C_{\mathrm{f}}=3183 \mathrm{kN}$ and in-plane (weak axis) moment $M_{\mathrm{fy}}=15 \mathrm{kN}-\mathrm{m}$ in the bottom tier column segment under compression. Second order effects should be included in this analysis but were not included here to ease understanding the relationship between bending moments and brace forces.

As discussed earlier, the columns must also resist concomitant strong axis bending moments due to transverse out-of-plane notional loads. In Fig. $4 \mathrm{~d}$, these loads induce a moment $M_{\mathrm{fx}}=394 \mathrm{kN}-$ $\mathrm{m}$ for the verification of the column segment in Tier 1 . Under this loading condition, the initially selected columns must be increased to W760x284. The frame lateral deflection is influenced by the column size and the nonlinear response shown in Fig. 4c depends on the column in-plane flexural stiffness. With the revised W760x284 columns, $\delta_{\text {roof }}$ reduces from 125 to $121 \mathrm{~mm}$ and the analysis is redone by imposing this roof lateral displacement. In Tier $1, C_{\mathrm{f}}$ in the column becomes $3186 \mathrm{kN}$ and $M_{\mathrm{fy}}$ is augmented to $17 \mathrm{kN}-\mathrm{m}$. The moment $M_{\mathrm{fx}}$ remains unchanged and W760x284 section is found be adequate to resist these revised actions. The analysis also shows that the drift in critical Tier 1 is $68 \mathrm{~mm}\left(0.68 \% h_{1}\right)$ when $\delta_{\text {roof }}$ is $121 \mathrm{~mm}$. Although not required in S16, the engineer should verify if this drift is acceptable. In this example, the height of the 
critical tier is relatively high, which resulted in moderate tier drift and column in-plane demand. As discussed below, more severe situations can be encountered for other critical tier scenarios or frame geometries.

In lieu of the above static analysis, column moments can be estimated using the three-moment equation with the anticipated frame deformation pattern at the target storey displacement. In the non-yielding tiers, the tier relative lateral deformation $\Delta_{\mathrm{i}}$ when brace yielding develops in the critical tier can be obtained from:

$$
\Delta_{i}=\Delta_{e, i} \frac{V_{u, c r}^{\prime}}{V}+\frac{V_{u, c r}^{\prime}-2 C_{u} \cos \theta_{i}}{\left(2 E A \cos ^{3} \theta_{i}\right) / L}
$$

where $\theta$ is the angle of the braces from horizontal, $E$ and $A$ are the Young's modulus of elasticity and the brace cross-sectional area, respectively, $V_{\mathrm{u}, \mathrm{cr}}^{\prime}$ is the storey shear resistance provided by the braces in the critical tier for the post-buckling brace condition, and $\Delta_{\mathrm{ei}}$ is the tier lateral deformation under the lateral load $V$. The deformation of the critical tier is obtained by removing the sum of the $\Delta_{\mathrm{i}}$ values of non-yielding tiers from the roof displacement $\delta_{\text {roof. }}$ The displacements at strut levels defining the frame deformation pattern are then obtained using these tier lateral deformations (Fig. 5a). For the frame example: $\delta_{1}=70 \mathrm{~mm}, \delta_{2}=95 \mathrm{~mm}$, and $\delta_{3}=\delta_{\text {roof }}=121$ mm. In-plane bending moments in the columns are then computed using the classical threemoment equation developed for determining bending moments in continuous beams on multiple supports subjected to relative support settlements. For a 3-tiered frame, this gives the following two equations that can be solved for $M_{\mathrm{fy} 1}$ and $M_{\mathrm{fy} 2}$ :

$$
\begin{aligned}
& 2 M_{f y 1}\left(h_{1}+h_{2}\right)+M_{f y 2} h_{2}=\frac{6 E I_{c}\left(\delta_{1}\right)}{h_{1}}-\frac{6 E I_{c}\left(\delta_{2}-\delta_{1}\right)}{h_{2}} \\
& M_{f y 1} h_{2}+2 M_{f y 2}\left(h_{2}+h_{3}\right)=\frac{6 E I_{c}\left(\delta_{2}-\delta_{1}\right)}{h_{2}}-\frac{6 E I_{c}\left(\delta_{3}-\delta_{2}\right)}{h_{3}} \\
& 12
\end{aligned}
$$


In these equations, $E I_{\mathrm{c}}$ is the flexural stiffness of the column. The remaining parameters are shown in Fig. 5a. For the frame example with the W760x284 columns and the calculated deformation pattern, the moments $M_{\mathrm{fy} 1}$ and $M_{\mathrm{fy} 2}$ are respectively equal to 23 and $7 \mathrm{kN}-\mathrm{m}$, which compares well with those obtained from the frame analysis. When applying the three-moment equation, column axial forces can be obtained from the analysis cases specified in CSA S16 for brace loading conditions (Figs. 4a and 4b).

\section{Alternative Critical Tier Scenarios}

As discussed, brace resistances may vary due to the unavoidable variabilities in material properties (yield strength), cross-sectional areas, cold working process, member imperfections and boundary conditions. For instance, variability in yield strength as reported by Schmidt and Bartlett (2002) may result in variations of $10-20 \%$ and $15-35 \%$ in axial strength of rolled W shape and HSS shape members, respectively. This variability may affect the location of the critical tier and all possible critical tier scenarios should be examined in design by reducing brace yield strengths in selected tiers by a given margin until they become the weakest. In the previous section, column design was performed assuming critical Tier 1 . In Table $1, V_{\mathrm{u}}$ in Tiers 2 and $3(1135 \mathrm{kN})$ is close to $V_{\mathrm{u}}$ in Tier $1(1097 \mathrm{kN})$ and the critical tier could be either Tier 2 or Tier 3 when considering that the actual brace resistances in the as-built frame may differ from the probable values in Table 1. Therefore, these other potential critical tier scenarios must also be investigated when verifying the columns. In Fig. 5b, results from static analysis are shown for the case where Tier 2 becomes critical by reducing the brace strengths by only $5 \%$ in that tier. In the analysis, both braces in Tier 2 and the compression braces in Tiers 1 and 3 are replaced by their probable actions and a roof displacement of $121 \mathrm{~mm}$ is imposed together with gravity loads. The final W760x284 columns were used in the analysis. The computed forces in the tension braces in 
Tiers 1 and 3 do not exceed $T_{\mathrm{u}}$ in these tiers, confirming the possibility of the critical Tier 2 scenario. For this loading condition, $C_{\mathrm{f}}$ is smaller $(2951 \mathrm{kN})$ in the lower column segment but the moment $M_{\text {fy }}$ has increased from 17 to $47 \mathrm{kN}-\mathrm{m}$ when compared to critical Tier 1 scenario. The drift in Tier 2 is $0.85 \% h_{2}$, larger than in the previous scenario. Similarly, the frame response and member forces when Tier 3 is critical are presented in Fig. 5c. These two scenarios result in larger moments $M_{\mathrm{fy}}$ near Tier 2 but the axial compression is smaller in the second tier.

For this frame example, critical Tier 1 scenario controlled column design but this may not be the case for another frame and all likely critical tier scenarios must be investigated to ensure adequate seismic response. In view of the variations in brace yield strengths and brace compression strength predictions, it is suggested that alternative critical tier scenarios should be investigated when $V_{\mathrm{u}}$ in a tier is within 1.1 to 1.15 times the minimum $V_{\mathrm{u}}$. When selecting critical tier, one may consider that: in shorter tiers, columns have relatively higher flexural stiffness and attract larger moments; column stability is generally more critical in taller tiers because of the longer in-plane buckling lengths; axial compression is maximum in bottom column segments and is typically larger when the critical tier is the bottom tier as compression braces in the other tiers resist loads equal to $C_{\mathrm{u}}$; and braces in shorter critical tiers generally are more prone to failure because they have shorter length to accommodate frame inelastic deformations.

Brace strength variability should be considered in calculation of unbalanced horizontal brace loads and column in-plane moments; however, brace compression resistances $C_{\mathrm{u}}$ and $C^{\prime}{ }_{\mathrm{u}}$ already represent upper and lower bound values respectively, which partly accounts for this variation. In design, column demands are obtained using $C_{\mathrm{u}}$ and $C^{\prime}$ u without modification. As was done in this example, when performing nonlinear analysis, brace strengths must be modified as necessary to trigger critical tier scenarios assumed in design. 


\section{Other Frame Configurations}

The above analysis technique and design method were adopted for the 3-tiered Type MD braced frame with identical tiers and the 5-tiered Type LD irregular frame of Fig. 3. For the 3-tiered frame, three critical tier scenarios were examined to design the columns. The critical Tier 1 scenario was the most severe. It resulted in larger moments $M_{\mathrm{fy}}(=28 \mathrm{kN}-\mathrm{m})$ compared to the non-uniform 3-tiered frame because of the shorter tier height. The concomitant axial load and out-of-plane moment in Tier 1 were $3144 \mathrm{kN}$ and $355 \mathrm{kN}-\mathrm{m}$ respectively. Due to shorter buckling length about weak axis $(6.667 \mathrm{~m})$, a smaller W610x217 column section was needed to satisfy the column strength and stability requirements. The anticipated roof deflection was $\delta_{\text {roof }}=$ $127 \mathrm{~mm}$ and the critical Tier 1 drift was found equal to $0.87 \% h_{1}$, larger than for the non-uniform 3 tiered frame because the frame inelastic deformations are concentrated in a shorter tier.

For the Type LD 5-tiered braced frame, a larger design seismic load $V=577 \mathrm{kN}$ was used because of the lower value for $R_{\mathrm{d}}(=2.0)$. Five critical tier scenarios were considered to obtain the in-plane bending demands and verify the columns. Column design was governed by the critical Tier 1 scenario triggered by reducing the brace strength in Tier 1 by $7 \%$. For this case, the columns in Tier 1 had to resist the combined forces $C_{\mathrm{f}}=3416 \mathrm{kN}, M_{\mathrm{fy}}=15 \mathrm{kN}-\mathrm{m}$, and $M_{\mathrm{fx}}=$ $612 \mathrm{kN}-\mathrm{m}$ and a W690x217 section was selected. The critical Tier 1 drift reached $0.73 \% h_{1}$ with $\delta_{\text {roof }}=125 \mathrm{~mm}$. For this frame, a larger $1.01 \% h_{2}$ drift was predicted in Tier 2 for the critical Tier 2 scenario.

\section{Seismic Response of MT-BFs}

\section{Numerical model and ground motions}

Nonlinear Response History (NLRH) analysis was performed using the numerical model shown 
in Fig. 6 to study the in-plane response of the prototype MT-BFs. The model was created using the OpenSees program 2.4.2 (McKenna and Fenves, 2004). In this model, columns and braces are modeled with fiber discretization of the cross-section using the force-based beam-column element. Past studies have shown that this model can reproduce adequately inelastic flexural buckling response under cyclic loading for HSS bracing members (Aguero et al. 2006; Uriz et al. 2008) and I-shaped columns (Lamarche and Tremblay 2011). The capability of the model to predict flexural buckling of I-shaped MT-BF columns was verified against three-dimensional finite element model (Imanpour et al. 2016b). In that study, column in-plane flexural buckling initiated under the large flexural demand and the buckling mode then progressively changed to bi-axial buckling due to out-of-plane deformations resulting from column plastic hinging. The uniaxial Steel02 material model was selected to account for Baushinger effect as well as isotropic and kinematic strain hardening behaviour. The material was defined with $E=200 \mathrm{GPa}$, and yield strengths $F_{y}$ of $345 \mathrm{MPa}$ for the columns and struts and $460 \mathrm{MPa}$ for the braces. Residual stresses were included in the model for the columns. Buckling of braces and columns was simulated by dividing each member into ten elements and using a co-rotational formulation to account for geometric nonlinearities. The braces were assigned an initial sinusoidal imperfection corresponding to their first out-of-plane buckling mode shape with a maximum amplitude of 0.001 times the buckling lengths. For the columns, bi-directional initial sinusoidal out-ofstraightness corresponding to the first in-plane and out-of-plane buckling modes was considered as shown in Fig. 6. Defect amplitudes were set equal to $h_{n} / 1000$ and $h_{\mathrm{i}} / 1000$ for out-of-plane and in-plane buckling, respectively, where $h_{\mathrm{i}}$ represents the tier heights. No initial out-of-plumbness was considered for the columns. The columns were pinned at their bases and roof level in in the plane and out of the plane of the frame. No out-of-plane restraint was considered at strut levels. 
Nonlinear rotational springs with strength and stiffness properties representing the rotational response of the brace gusset plates under out-of-plane buckling of the braces were assigned at the ends of the continuous bracing members and discontinuous brace segments. The struts were modeled using elastic beam-column elements. Rigid elastic truss and beam-column elements were used to reproduce connection sizes. Additional information on the numerical model can be found in Imanpour et al. (2016b).

Gravity loads were applied to the columns and the model also included a P-delta column represented by a co-rotational truss element that carried the remaining frame tributary gravity loads. Point masses representing the frame tributary seismic weight were applied at top of the columns. Rayleigh mass proportional damping equal to $2 \%$ of critical in the first mode of vibration was used to model the inherent damping of the building. A group of 21 ground motions were selected and scaled to match, on average, the NBCC design spectrum for Vancouver using the method presented in Dehghani and Tremblay (2015).

\section{In-Plane Seismic Response}

The $50^{\text {th }}$ (median) and $84^{\text {th }}$ percentile values of peak response parameters from the 21 ground motions are presented in Table 2 for the three prototype structures. The 5-tiered frame is discussed at the end of the section. For the non-uniform 3-tiered Type MD frame, the NLRH analyses were performed twice: 1 ) with $R_{\mathrm{y}} F_{\mathrm{y}}=460 \mathrm{MPa}$ for all braces, and 2) with $0.95 R_{\mathrm{y}} F_{\mathrm{y}}=437$ MPa for the braces in Tier 3 to create a critical Tier 3 scenario. In the table, the values in brackets are the results from the second analysis. For the uniform 3-tiered frame, a reduced yield strength of $437 \mathrm{MPa}$ was assigned to the braces in Tier 1 to intentionally initiate brace yielding in that tier. In the three cases, the frames exhibited stable response without column buckling under any of the ground motion records. Median peak storey drifts are close to the anticipated roof drift $\left(R_{\mathrm{d}} R_{\mathrm{o}} \delta_{\mathrm{e}}\right)$. 
The peak drifts induced in the critical tiers are larger than the roof drifts, confirming non-uniform drift demands along frame heights. This behaviour is reflected by the Drift Concentration Factor (DCF), which compares the maximum critical tier drift to the storey drift. The uniform 3-tiered frame experienced larger critical tier drifts than its non-uniform counterpart due to a shorter critical tier. The same observation can be made between the critical Tier 3 and critical Tier 1 scenarios for the non-uniform frame. In Table 2, median in-plane bending demands in the columns $\left(M_{\mathrm{cy}}\right)$ are also well predicted for the two 3-tiered frames. In Fig. 7a, peak frame lateral displacement and column bending moment envelopes from the individual ground motion records are given together with median values for the non-uniform 3-tiered frame. An excellent match is observed between the median NLRH analysis results and design predictions for both critical tier scenarios.

Among the applied ground motions, those imposing larger storey drifts also induce more pronounced deformations in the critical tiers and, thereby, larger flexural demands on the columns. This trend is confirmed when comparing $84^{\text {th }}$ and $50^{\text {th }}$ percentile results in Table 2: the differences between the two sets of values are more pronounced for the critical tier drift and DCF compared to those observed for the storey drifts. This was expected as additional frames lateral deformations induced by the more severe ground motions tend to concentrate in the critical tiers. As a result, the $84^{\text {th }}$ percentile bending moments significantly exceeded the values considered in design, with NLRH/design ratios reaching 2.75, 1.84 and 2.83 for the three cases. Although column instability was not observed in the analyses, such large bending moments should probably be accounted for in design by using larger storey drifts. The proposed static analysis method was found adequate to predict this higher demand. For instance, for the non-uniform 3tiered CBF with Tier 1 critical, the method predicts a drift and a column moment in the critical tier equal to $1.0 \% h_{1}$ and $0.06 M_{\text {py }}$, respectively, if the $84^{\text {th }}$ percentile storey displacement 
obtained from NLTH analysis is used in the frame analysis. These two values match well the corresponding $84^{\text {th }}$ percentile NLRH analysis results $\left(0.93 \% h_{1}\right.$ and $\left.0.06 M_{\text {py }}\right)$ in Table 2.

The analysis of the non-uniform 5-tiered Type LD frame was performed using reduced $R_{\mathrm{y}} F_{\mathrm{y}}=$ $437 \mathrm{MPa}$ in Tier 5 to reproduce the critical tier scenario considered in design that induced maximum moments at Tier 4. As expected from the lower $R_{\mathrm{d}}$ value used in design, limited inelastic response took place in the braces; nevertheless, as indicated in Table 2, inelastic drifts only developed in Tier 5 and the largest bending moments developed at Tier 4, as anticipated. Critical tier drifts and DCFs are similar to those observed for the 3-tiered frames, which indicates that restricting 4- and 5-tiered frames to the Type LD CBF category, as specified in CSA S16-14, is an adequate means of achieving consistent frame response for this system. In counterpart, median column flexural demands for this frame are less than predicted in design. Compared to Type MD frames, the larger columns in the frame better distribute deformation demands between tiers. Here, brace yielding also developed in identical Tier 4, which led to smaller column bending. Also, brace ductility demand in Type LD is lower which reduces the unbalanced brace load resultants applied to the columns compared to the values assumed in design. This shows that, the assumption made in S16 that inelastic deformations are limited to a single tier over the storey height may lead to conservative bending moment estimates for such frames with multiple identical tiers. As discussed in the next section, this assumption may not be valid for tall MT-BFs designed for more ductile response and an extended analysis and design approach is proposed that more closely reflects the actual frame response.

\section{Extended Analysis and Design Approach for Tall Type MD CBFs}

In CSA S16, limits are specified on the number of tiers to prevent excessive tier drifts and brace ductility demand in MT-BFs. Taller frames may be needed for some building applications and an 
extended analysis and design approach is introduced in this section for such frames. In this approach, both analysis techniques presented above can be used to obtain column demands and tier drifts. This approach is illustrated for the 5-tiered Type MD frame with non-uniform tier heights shown in Fig. 8a. The frame exceeds the 3-tier limit of CSA S16-14. It is first designed in accordance with current S16 provisions assuming that brace tension yielding develops only in one tier. The design is then revised to reflect the actual frame response. In this example, the static analysis technique was used.

For this frame, $V=389 \mathrm{kN}$ and two brace sizes are used over the frame height: HSS $127 \times 127 \times 6.4$ in Tier 1 and HSS $88.9 \times 88.9 \times 4.8$ in Tiers 2 to 5 . The resulting probable shear resistances $V_{\mathrm{u}}$ are $1127 \mathrm{kN}$ for Tier 1, $870 \mathrm{kN}$ for Tiers 2 and 3, and $922 \mathrm{kN}$ for Tiers 4 and 5 . Four critical tier scenarios (2 to 5) were therefore studied and W760x257 columns were selected based on the critical Tier 2 scenario. Final design forces for this case are shown in Fig. $8 \mathrm{~b}$ for $\delta_{\text {roof }}=154 \mathrm{~mm}$. For this brace loading scenario, Tier 2 drift reaches $1.47 \% h_{2}$ and Tier 1 columns must resist the combined forces $C_{\mathrm{f}}=2767 \mathrm{kN}, M_{\mathrm{fx}}=515 \mathrm{kN}-\mathrm{m}$, and $M_{\mathrm{fy}}=161 \mathrm{kN}-\mathrm{m}$.

As shown in Fig. 8b, the brace axial force in Tier 3 is $845 \mathrm{kN}$, which exceeds $T_{\mathrm{u}}=667 \mathrm{kN}$ for HSS $88.9 \times 88.9 \times 4.8$ braces. This indicates that brace tension yielding in that tier will also initiate before the roof displacement reaches the anticipated value, contrary to the assumption of brace yielding in only one tier implicit in the CSA S16 seismic provisions. The analysis procedure must therefore be modified to account for the expected propagation of brace yielding along the frame height as illustrated in Fig. 9a. This is done by performing successive analysis steps corresponding to initiation of brace yielding in the frame until the anticipated roof drift is attained. Each analysis step includes static analysis of the frame for which the braces that have reached their probable resistances are removed and replaced by axial forces corresponding to 
their probable resistances.

This first analysis step is performed with the initially designed W760x257 columns and the results are shown in Fig. 9b. In this analysis, it is found that a roof displacement of $120 \mathrm{~mm}$ is required to reach a brace tension force equal to $T_{\mathrm{u}}=667 \mathrm{kN}$ in Tier 3, which gives the column axial forces and bending moments shown in Fig. 9b. Using these values together with the out-of-plane bending moments from notional loads reduced the column size to W690x217. This first analysis step is redone with this new section to obtain consistent forces and moments at brace yielding initiation in Tier 3. It is found that brace yielding occurs at a roof displacement equal to $128 \mathrm{~mm}$ and the W690x217 columns are sufficient to resist the corresponding demands. For the second analysis step, the tension brace in Tier 3 is removed from the model and replaced by $T_{\mathrm{u}}$ and a roof displacement equal to $\delta_{\text {roof }}=160 \mathrm{~mm}$ predicted with the W690x217 columns is applied. As shown in Fig. 9c, this results in brace tension forces of 605 and $498 \mathrm{kN}$ in Tiers 4 and 5, less than $T_{\mathrm{u}}=667$ $\mathrm{kN}$ in these tiers, and $729 \mathrm{kN}$ in Tier 1 , also less than $T_{\mathrm{u}}=1274 \mathrm{kN}$ in that tier. This shows that no further brace yielding is expected when the frame attains the anticipated roof drift and the analysis is halted at this step. Comparing the brace tension forces to $T_{\mathrm{u}}$ in each tier reveals that brace tension yielding would occur in Tier 4 if the frame drift was to exceed $R_{\mathrm{d}} R_{\mathrm{o}} \delta_{\mathrm{e}}$. The selected W690x 217 columns are found sufficient to resist the forces induced in this second analysis step. Compared to the results shown in Fig. 8b, column bending moments in both steps are reduced because brace yielding develops in two tiers instead of only one, which gives smaller column flexural deformations. Column axial compression forces also diminished under the more realistic brace forces considered in the modified analysis method. Drifts are expected to reach $1.47 \% h_{2}$ and $1.44 \% h_{3}$ in Tiers 2 and 3 respectively. At this point, if needed, the column stiffness could be increased to reduce tier drift by triggering yielding in a third tier. The column strength would then 
be verified to resist forces from analysis steps representing this modified brace yielding pattern.

NLRH analysis of this frame was performed under the same suite of ground motions and considering 5\% reduction in brace yield strength in Tier 2 to replicate the governing design conditions. No column instability occurred in the analyses and statistics of the response are given in Table 3, including the range of values obtained in NLRH analysis. As shown, the NBCC storey drift lies between the median and $84^{\text {th }}$ percentile analysis results. In Fig. 7c, very good agreement is observed between design frame lateral deformations and median time history displacement values. As predicted in design, inelastic brace deformations mainly distributed between Tiers 2 and 3. Under stronger ground motions, as also expected from the frame analysis, brace tension yielding also extended to Tier 4 and even Tier 5, which resulted in more uniform tier drift response in the top 4 tiers. Median peak drifts in Tiers 2 and 3 are therefore smaller than obtained from frame analysis but the $84^{\text {th }}$ percentile values are close to the design predictions. The ratio of NLRH analysis to design column in-plane bending demand is close 1.0 in Tiers 1 and 3 , confirming the appropriateness of the modified analysis procedure for flexural demand. In Fig. 9b, lesser than expected bending demand was induced at Tier 2, which is attributed to the fact that brace tension yielding took place nearly simultaneously in identical Tiers 2 and 3 in the NLRH analysis, when forces in compression braces in both tiers were nearly same. However, the good match in moments at Tiers 1 and 3 show that design conditions in fact develop when differences in brace resistances are sufficient to delay or prevent brace tension yielding in other tiers.

This example shows that the proposed extended analysis and design approach accounts for the progression of brace yielding that characterizes the seismic response of tall MT-BFs with a large number of tiers. The extended approach results in smaller column bending moment demands compared to current S16 method, which may translate in smaller steel tonnage. The extended 
approach can also be used to control the frame response by selecting column sections required to develop the required number of yielding tiers so that tier drifts remain within acceptable limits over the frame height.

\section{Conclusions}

Unlike typical multi-storey braced frames, multi-tiered braced frames are likely to exhibit unsatisfactory response due to unbalanced brace loads and non-uniform drift response that must be considered in design. In this paper, seismic design provisions of CSA S16 for MT-BFs were presented and illustrated for three prototype multi-tiered X-braced frames. Simple analysis methods including a computer-based static analysis technique and three-moment equation based method were proposed to determine column design forces and tier drifts consistent with CSA S16. NLRH analysis was performed to examine the seismic behaviour of the prototype frames and validate CSA S16 provisions. The current design approach and the proposed static analysis technique were extended to tall MT-BFs in which brace tension yielding is expected to propagate in more than one tier. A 5-tiered CBF example was used to illustrate this extended approach and the frame response was examined through NLRH analysis. The main conclusions are summarized as follows:

- The proposed simple analysis techniques can be used to analyze and design MT-BFs with uniform or non-uniform properties and frames where brace inelastic deformations distribute in several tier.

- Response history analysis showed that frames complying with CSA S16 limitations develop brace tension yielding essentially in one tier without excessive tier drifts. The seismic induced column in-plane flexural bending demand can be well predicted when applying 
CSA S16 requirements.

- The study showed that multiple critical tier scenarios, resulting in different tier drift and force demands, may develop in MT-BFs and must be considered in design.

- Seismic force and deformation demands from NLRH analysis were well predicted by the proposed analysis techniques. For the frame exceeding the CSA S16 limits on number of tiers, the frame actual inelastic response, including the sequence of brace tension yielding, was properly tracked by the proposed extended approach.

- Allowing brace tension yielding in more than one tier can lead to more economical column designs compared to current CSA S16 provisions.

- In-plane moment demand on the columns was found to be sensitive to the storey drifts assumed in design. Representative storey drift estimates should therefore be used to avoid underestimating moments in columns.

The extended design approach can be used as tools to control the frame response by selecting frame configuration, bracing members, and/or column sections to achieve desired seismic performance. The design procedure only addresses in-plane seismic response. Future studies should investigate the appropriateness of the current out-of-plane notional loads as specified in CSA S16 and examine column stability under coupled in-plane and out-of-plane flexural demands.

\section{Acknowledgments}

Funding from the Natural Sciences and Engineering Research Council (NSERC) of Canada is acknowledged. The authors would like to thank the anonymous reviewer for their constructive comments and helpful suggestions to improve the quality of the paper. 


\section{References}

Aguero, A., Izvernari, C., and Tremblay, R. 2006. Modelling of the Seismic Response of Concentrically Braced Steel Frames using the OpenSees Analysis Environment, Int. J. of Advanced Steel Construction. 2(3): 242-274.

CSA. 2009, 2014. CSA-S16-09, CSA-S16-14, Design of Steel Structures. Canadian Standards Association, Mississauga, ON.

CISC. 2001. Handbook of steel construction. Canadian Institute of Steel Construction (CISC). Toronto, ON.

Dehghani, M., and Tremblay, R. 2015. Robust Period-Independent Ground Motion Selection and Scaling for Effective Seismic Design and Assessment, Journal of Earthquake Engineering. 20(2): 185-218. DOI: 10.1080/13632469.2015.1051635.

Imanpour, A., Tremblay, R., and Davaran, A. 2012a. Seismic performance of steel concentrically braced frames with bracing members intersecting columns between floors. Proceedings of the $7^{\text {th }}$ STESSA Conference, Santiago, Chile, 9-11 January. Edited by F. Mazzolani and R. Herrera. Taylor \& Francis, Leiden, The Netherlands. pp. 447-453.

Imanpour, A., Tremblay, R., and Davaran, A. 2012b. Seismic Evaluation of Multi-Panel Steel Concentrrically Braced Frames. Proceedings of the $15^{\text {th }}$ World Conf. on Earthquake Eng., Lisbon, Portugal, 24-28 September. Paper No. 2996.

Imanpour, A., and Tremblay, R. 2014a. Seismic performance evaluation and design of multitiered steel concentrically braced frames. $10^{\text {th }}$ U.S. National Conference on Earthquake Engineering, 10NCEE. Anchorage, AK, 21-25 July. Paper No. 1347.

Imanpour, A., and Tremblay, R. 2014b. Seismic design of steel multi-tiered braced frames: Application of incremental static analysis for design of steel multi-tiered braced frames. 
Eurosteel 2014, Naples, Italy, 10-12 September, Edited by R. Landolfo and F. Mazzolani. ECCS European Convention for Constructional Steelwork, Brussels, Belgium, Paper No. 688.

Imanpour, A., Auger K., and Tremblay, R. 2016a. Seismic design and performance of multitiered steel braced frames including the contribution from gravity columns under in-plane seismic demand. Advances in Engineering Software. Available from http://dx.doi.org/10.1016/j.advengsoft.2016.01.021.

Imanpour, A., Tremblay, R., Davaran, A., Stoakes, C., and Fahnestock, L. 2016b. Seismic Performance Assessment of Multi-Tiered Steel Concentrically Braced Frames Designed in Accordance with Current AISC Seismic Provisions. J. Struct. Eng. ASCE. DOI: 10.1061/(ASCE)ST.1943-541X.0001561.

Lamarche, C.P., Tremblay, R. 2011. Seismically induced cyclic buckling of steel columns including residual-stress and strain-rate effects. J. of Constr. Steel Res. 67(9): 1401-1410.

McKenna, F. and Fenves, G.L. 2014. Open System for Earthquake Engineering Simulation (OpenSees). Pacific Earthquake Engineering Research Center (PEER), University of California, Berkeley, CA. (http://opensees.berkeley.edu/)

NRCC. 2015. National Building Code of Canada, $14^{\text {th }}$ ed. National Research Council of Canada. Ottawa, ON.

Schmidt, B.J., and Bartlett F.M. 2002. Review of resistance factor for steel: data collection. Can. J. Civ. Eng. 29: 98-108.

Uriz, P., Filippou, F.C., Mahin, S.A. 2008. Model for cyclic inelastic buckling for steel member. J. Struct. Eng., ASCE, 134(4): 619-628. 
Table 1. Brace properties for the uniform 3-tiered Type MD CBF.

\begin{tabular}{ccccccccccccc}
\hline Tier & $\begin{array}{c}\mathrm{HSS} \\
\text { Braces }\end{array}$ & $\begin{array}{c}A \\
\mathrm{~mm}^{2}\end{array}$ & $\begin{array}{c}r_{x} \\
\mathrm{~mm}\end{array}$ & $K l / r$ & $\begin{array}{c}C_{\mathrm{f}} \\
\mathrm{kN}\end{array}$ & $\begin{array}{c}C_{\mathrm{r}} \\
\mathrm{kN}\end{array}$ & $\begin{array}{c}C_{\mathrm{f}} / \\
C_{\mathrm{r}}\end{array}$ & $\begin{array}{c}T_{\mathrm{u}} \\
\mathrm{kN}\end{array}$ & $\begin{array}{c}C_{\mathrm{u}} \\
\mathrm{kN}\end{array}$ & $\begin{array}{c}C_{\mathrm{u}}^{\prime} \\
\mathrm{kN}\end{array}$ & $\begin{array}{c}V_{\mathrm{u}} \\
\mathrm{kN}\end{array}$ & $\begin{array}{c}V^{\prime} \\
\mathrm{kN}\end{array}$ \\
\hline $2 \& 3$ & $102 \times 102 \times 6.4$ & 2170 & 38.6 & 91 & 259 & 326 & 0.80 & 998 & 479 & 200 & 1135 & 920 \\
1 & $127 \times 127 \times 7.9$ & 3390 & 48.3 & 109 & 395 & 401 & 0.98 & 1559 & 573 & 312 & 1097 & 963 \\
\hline
\end{tabular}

Table 2. MT-BFs studied: Statistics of peak frame response from NLRH analyses.

\begin{tabular}{lcccccc}
\hline Frame & \multicolumn{2}{c}{$\begin{array}{c}\text { Non-uniform 3-tiered } \\
\text { Type MD CBF }\end{array}$} & $\begin{array}{c}\text { Uniform 3- } \\
\text { tiered Type } \\
\text { MD CBF }\end{array}$ & $\begin{array}{c}\text { Non-uniform 5- } \\
\text { tiered Type LD } \\
\text { CBF }\end{array}$ \\
\hline Parameter & $50^{\text {th }}$ & $84^{\text {th }}$ & $50^{\text {th }}$ & $84^{\text {th }}$ & $50^{\text {th }}$ & $84^{\text {th }}$ \\
\hline Total storey drift $(\% h)$ & $0.63[0.63]$ & $0.77[0.77]$ & 0.63 & 0.80 & 0.56 & 0.74 \\
$\delta_{\text {roof,NLH }} / R_{\mathrm{d}} R_{\mathrm{o}} \delta_{\mathrm{e}}$ & $1.04[1.04]$ & $1.27[1.28]$ & 1.00 & 1.26 & 0.90 & 1.19 \\
Critical tier drift $\left(\% h_{\text {cr }}\right)$ & $0.68[0.81]$ & $0.93[1.19]$ & 0.77 & 1.27 & 0.85 & 1.30 \\
Critical tier drift $(\mathrm{NLRH} /$ design) & $1.00[0.87]$ & $1.37[1.28]$ & 0.89 & 1.50 & 0.66 & 1.01 \\
DCF & $1.06[1.29]$ & $1.21[1.51]$ & 1.19 & 1.58 & 1.48 & 1.77 \\
Column moment in Tier & $1[2]$ & $1[2]$ & 1 & 1 & 4 & 4 \\
$M_{\text {cy,NLRH }} / M_{\text {py }}$ & $0.03[0.10]$ & $0.06[0.16]$ & 0.06 & 0.15 & 0.10 & 0.22 \\
$M_{\text {cy-NLRH }} / M_{\text {cy-design }}$ & $1.15[1.15]$ & $2.75[1.84]$ & 1.13 & 2.83 & 0.53 & 1.16 \\
\hline
\end{tabular}

Table 3. Statistics of peak frame response from NLRH analyses for frame designed according to the proposed method.

\begin{tabular}{lccc}
\hline Frame & Non-uniform 5-tiered Type MD CBF & \\
\hline Parameter & $50^{\text {th }}$ & $84^{\text {th }}$ & range \\
\hline Total storey drift $(\% h)$ & 0.72 & 0.92 & $(0.49-1.33)$ \\
$\delta_{\text {roof,NLRH }} / R_{\mathrm{d}} R_{\mathrm{o}} \delta_{\mathrm{e}}$ & 0.91 & 1.15 & $(0.61-1.66)$ \\
Tier 3 drift $\left.\% h_{3}\right)$ & 1.22 & 1.64 & $(0.73-2.31)$ \\
Tier 3 drift (NLRH / design) & 0.85 & 1.14 & \\
Tier 2 drift $\left(\% h_{2}\right)$ & 1.16 & 1.44 & $(0.65-1.96)$ \\
Tier 2 drift (NLRH / design) & 0.79 & 0.98 & \\
Tier 1 drift (\% $\left.h_{1}\right)$ & 0.31 & 0.33 & $(0.29-0.37)$ \\
DCF & 1.69 & 1.77 & $(1.44-1.80)$ \\
$M_{\text {cy,NLRH }} / M_{\text {py }}($ Tier 3) & 0.17 & 0.20 & \\
$M_{\text {cy-NLRH }} / M_{\text {cy-design }}($ Tier 3) & 0.77 & 0.90 & \\
$M_{\text {cy,NLRH }} / M_{\text {py }}$ (Tier 2) & 0.02 & 0.04 & \\
$M_{\text {cy-NLRH }} / M_{\text {cy-design }}($ Tier 2) & 0.13 & 0.27 & $(0.01-0.05)$ \\
$M_{\text {cy,NLRH }} / M_{\text {py }}$ (Tier 1) & 0.19 & 0.23 & \\
$M_{\text {cy-NLRH }} / M_{\text {cy-design }}($ Tier 1) & 0.95 & 1.15 & \\
\hline
\end{tabular}


Fig. 1. a) Three-tiered concentrically steel braced frame with X-bracing; b) Flexural demand on MT-BF columns without intermediate struts; c) Non-uniform distribution of inelastic deformations in a MT-BF inducing in-plane flexural demand on columns and large inelastic demand on bracing members; d) Column out-of-plane buckling mode.

Fig. 2. a) Brace induced loading conditions for the design of brace connections, beams, and columns of Type MD and Type LD CBFs; b) Brace hysteretic response.

Fig. 3. Three braced frames studied: a) Non-uniform and uniform 3-tiered Type MD CBFs; b) Non-uniform 5-tiered Type LD CBF.

Fig. 4. Seismic analysis of the non-uniform 3-tiered Type MD CBF: a) Axial compression in struts under loading condition with all compression braces in the post-buckling range; b) Axial column loads under gravity and brace loading condition with all compression braces at buckling; c) Axial loads and bending moments in columns from nonlinear static analysis assuming inelastic demand concentrated in Tier 1; and d) Out-of-plane bending moments due to transverse notional loads. $\left(T_{\mathrm{u} 1}=1559, C_{\mathrm{u} 1}=573, C^{\prime}{ }_{\mathrm{u} 1}=312, T_{\mathrm{u} 2-3}=998, C_{\mathrm{u} 2-3}=479, C^{\prime}{ }_{\mathrm{u} 2-3}=200, P_{\mathrm{G}}=232\right.$; forces in $\mathrm{kN}$, moments in $\mathrm{kN}-\mathrm{m}$ )

Fig. 5. a) Calculation of the in-plane flexural demand on the column using three-moment equation; b) Nonlinear response of the non-uniform 3-tiered Type MD CBF for critical Tier 2; and c) Nonlinear response of the non-uniform 3-tiered Type MD CBF for critical Tier 3. $\left(T_{\mathrm{u} 1}=\right.$ $1559, C_{\mathrm{u} 1}=573, C^{\prime}{ }_{\mathrm{u} 1}=312, T_{\mathrm{u} 2-3}=998, C_{\mathrm{u} 2-3}=479, C^{\prime}{ }_{\mathrm{u} 2-3}=200 ; P_{\mathrm{G}}=232 ;$ forces in $\mathrm{kN}$, moments in $\mathrm{kN}-\mathrm{m}$ )

Fig. 6. Finite element model of the 3-tiered braced frame.

Fig. 7. Frame lateral displacement and column in-plane bending demands for a) 3-tiered Type MD CBF; and b) 5-tiered Type MD CBF. 
Fig. 8. 5-tiered Type MD CBF: a) Configuration and member sizes; b) Brace forces, axial loads and bending moments from nonlinear static analysis assuming inelastic demand concentrated in Tier 2. $\left(C_{\mathrm{u} 1}=604, T_{\mathrm{u} 2-3}=667, C_{\mathrm{u} 2-3}=326, C^{\prime}{ }_{\mathrm{u} 2-3}=133, C_{\mathrm{u} 4-5}=344 ; P_{\mathrm{G}}=232\right.$; forces in $\mathrm{kN}$, moments in $\mathrm{kN}-\mathrm{m}$ forces in $\mathrm{kN}$, moments in $\mathrm{kN}-\mathrm{m}$, displacement in $\mathrm{mm}$ )

Fig. 9. a) Progressive brace yielding for a 5-tiered CBF; b) Modified analysis for 5-tiered Type MD CBF at brace tension yielding in Tier 3 (Analysis 1); and c) Modified analysis for 5-tiered Type MD CBF at anticipated roof drift (Analysis 2$).\left(C_{\mathrm{u} 1}=604, T_{\mathrm{u} 2-3}=667, C_{\mathrm{u} 2-3}=326, C^{\prime}{ }_{\mathrm{u} 2-3}=\right.$ 133, $C_{\mathrm{u} 4-5}=344 ; P_{\mathrm{G}}=232$; forces in $\mathrm{kN}$, moments in $\mathrm{kN}-\mathrm{m}$ forces in $\mathrm{kN}$, moments in $\mathrm{kN}-\mathrm{m}$, displacement in $\mathrm{mm}$ ) 
b)

c) Codian Inurnal f Civil Enginooring

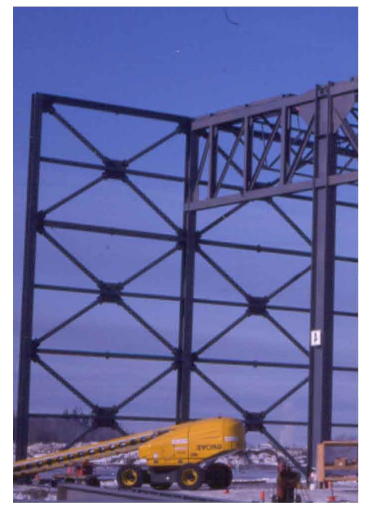

b)

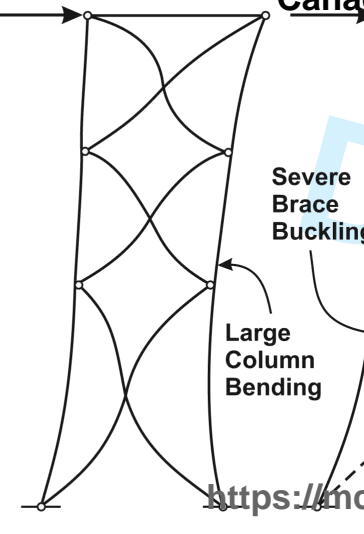

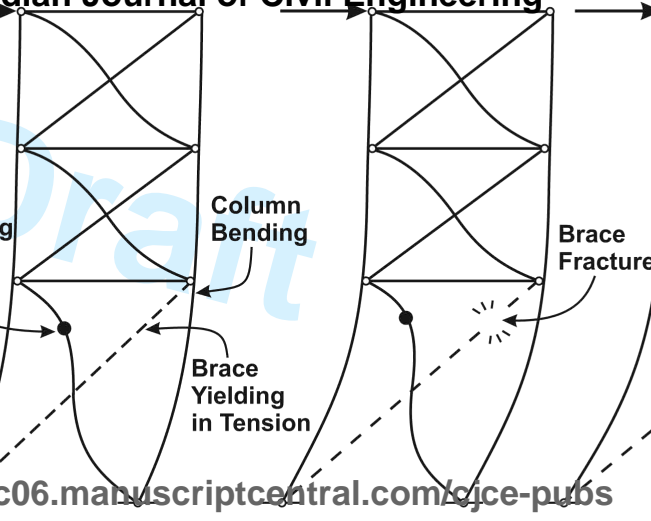

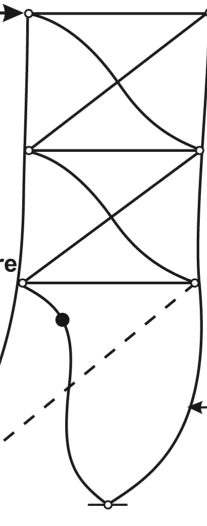

Column

Out-of-plane

Buckling

Column

In-plane Buckling

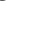


a)
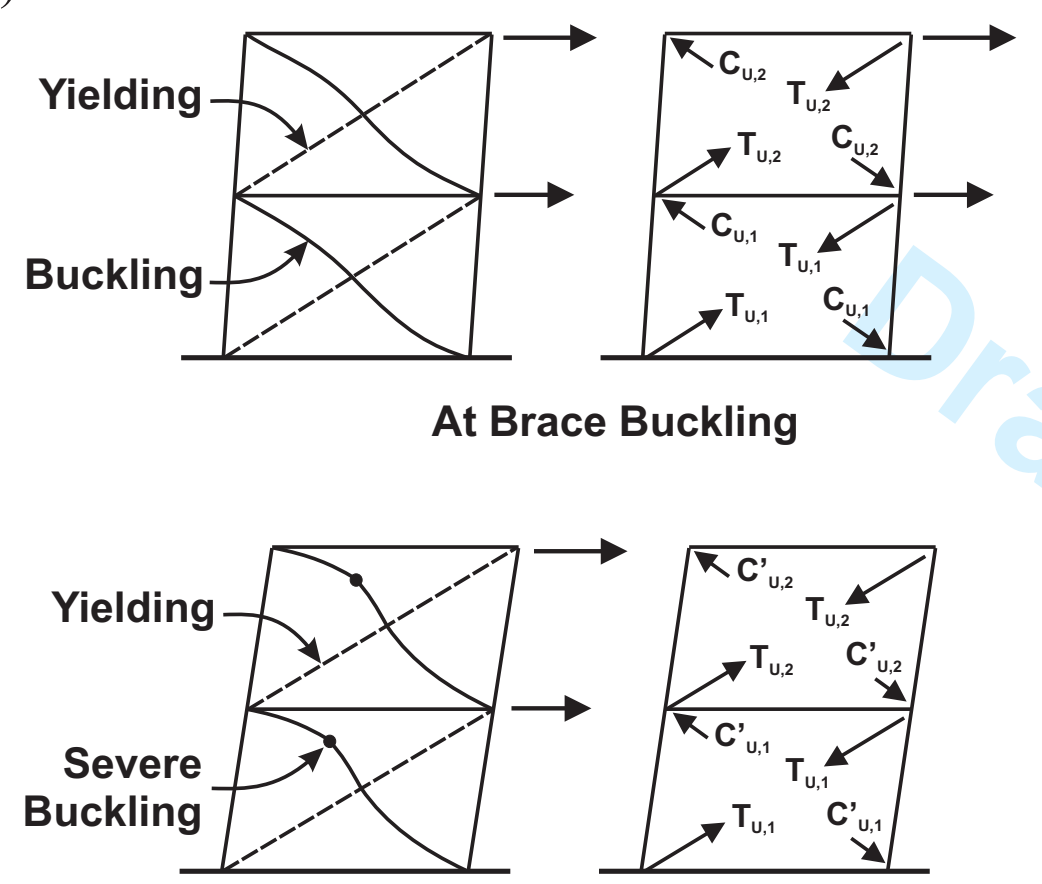

In Post-Buckling Range

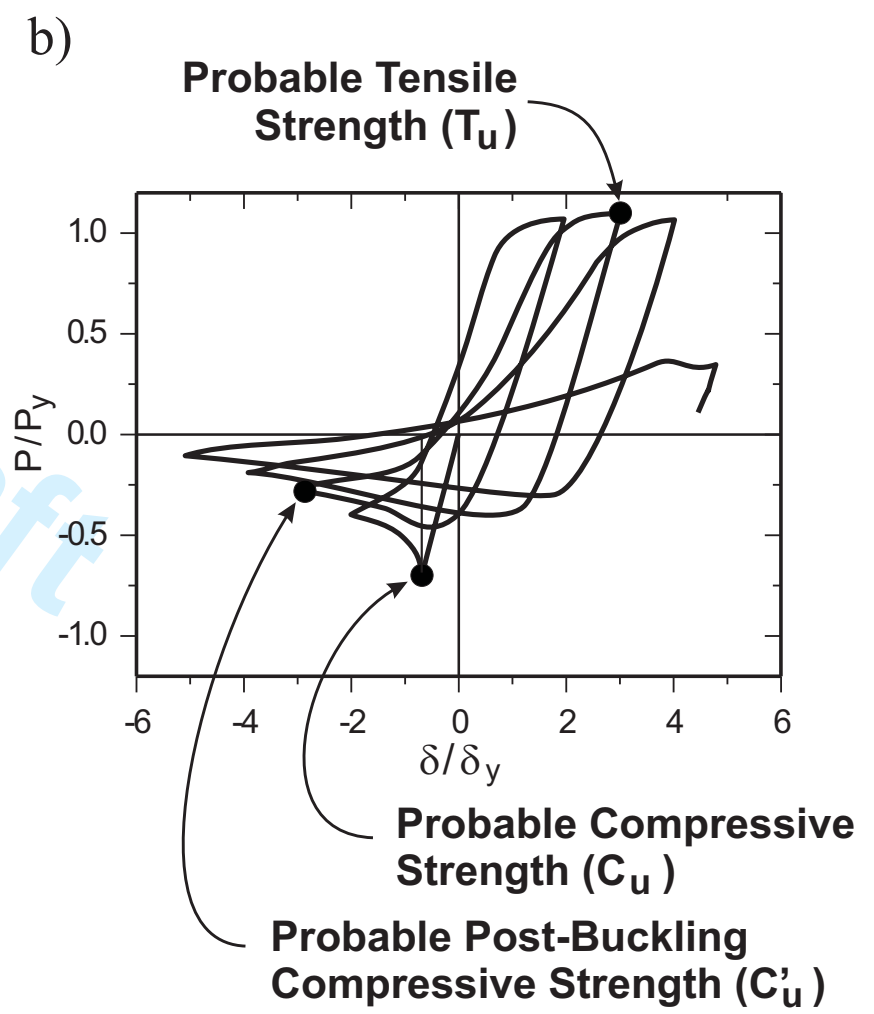


a)

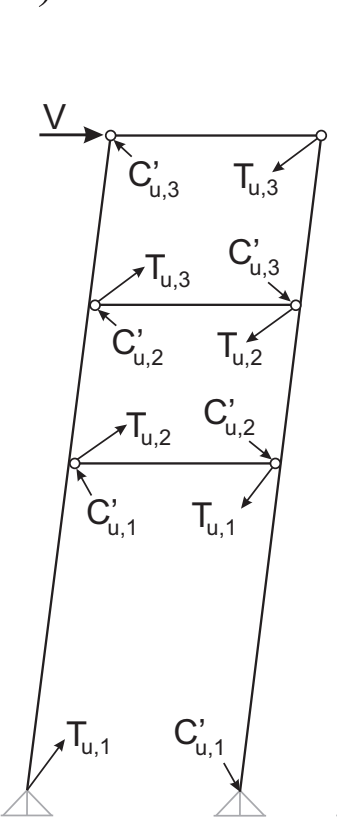

Brace Forces b)

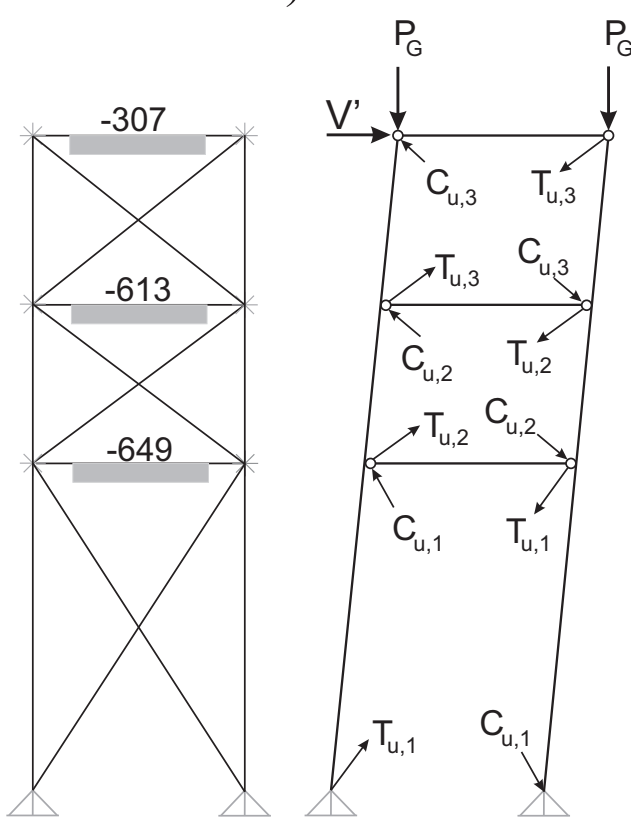

$\mathrm{C}_{\mathrm{f}} \quad$ Brace Forces c)

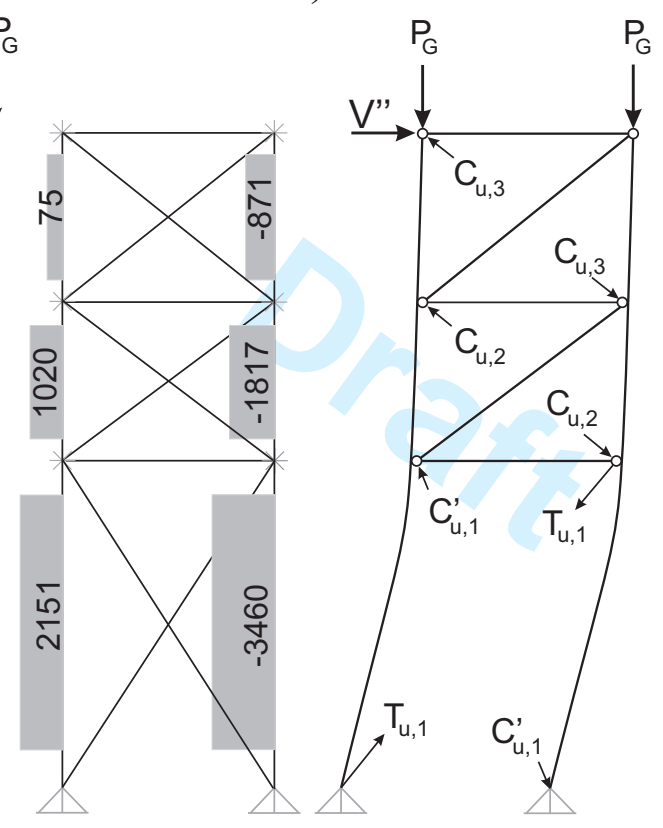

$\mathrm{C}_{\mathrm{f}} \quad$ Brace Forces

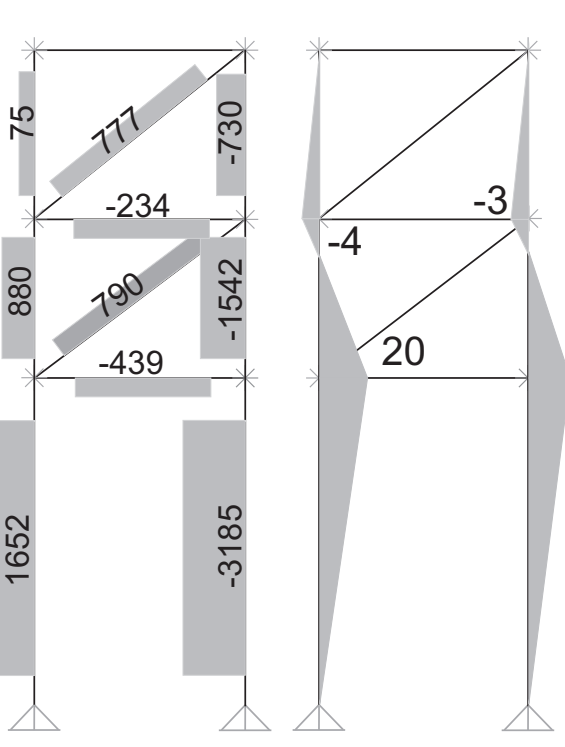

$C_{f}-T_{f}$ d)

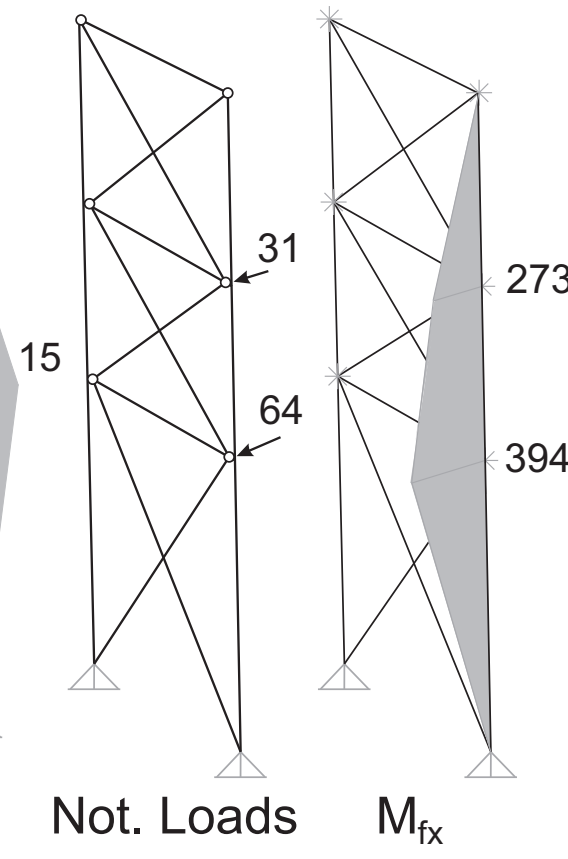


a)

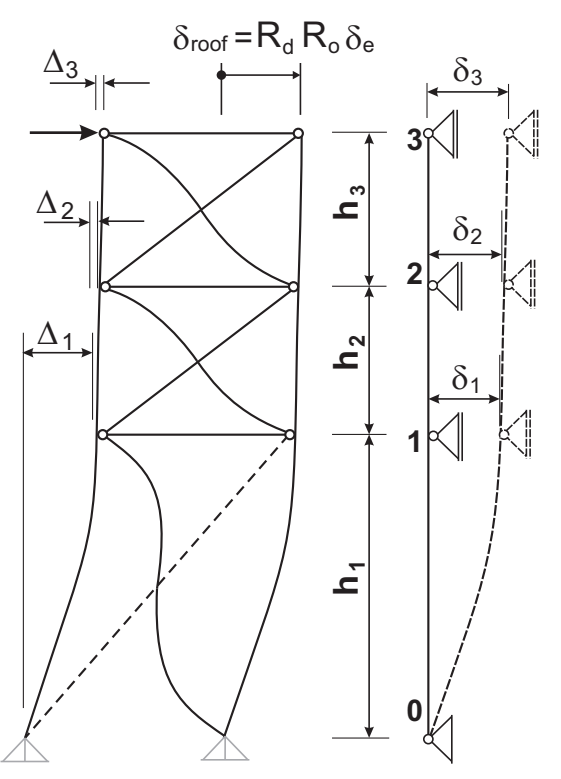

b)

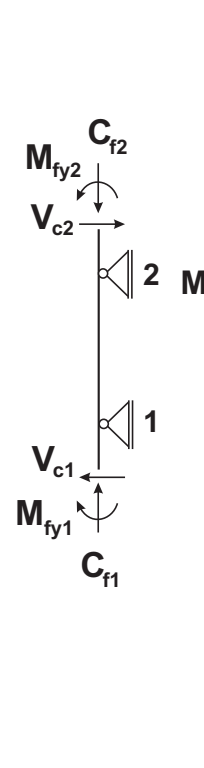

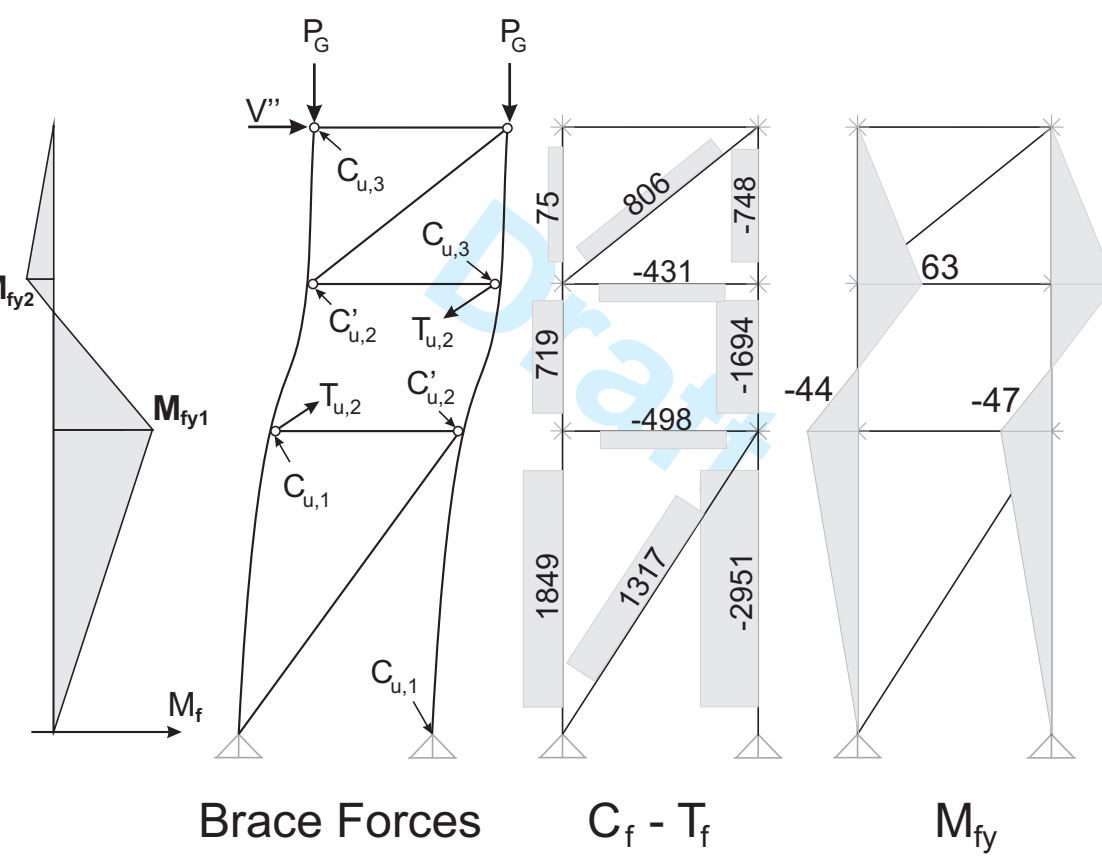

c)

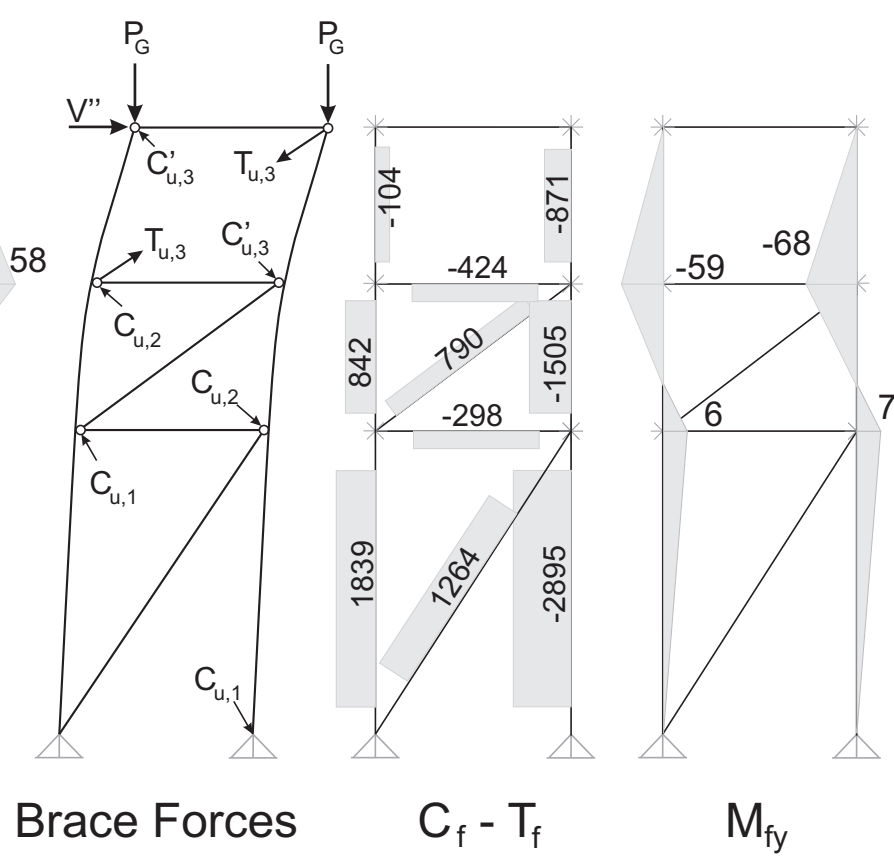




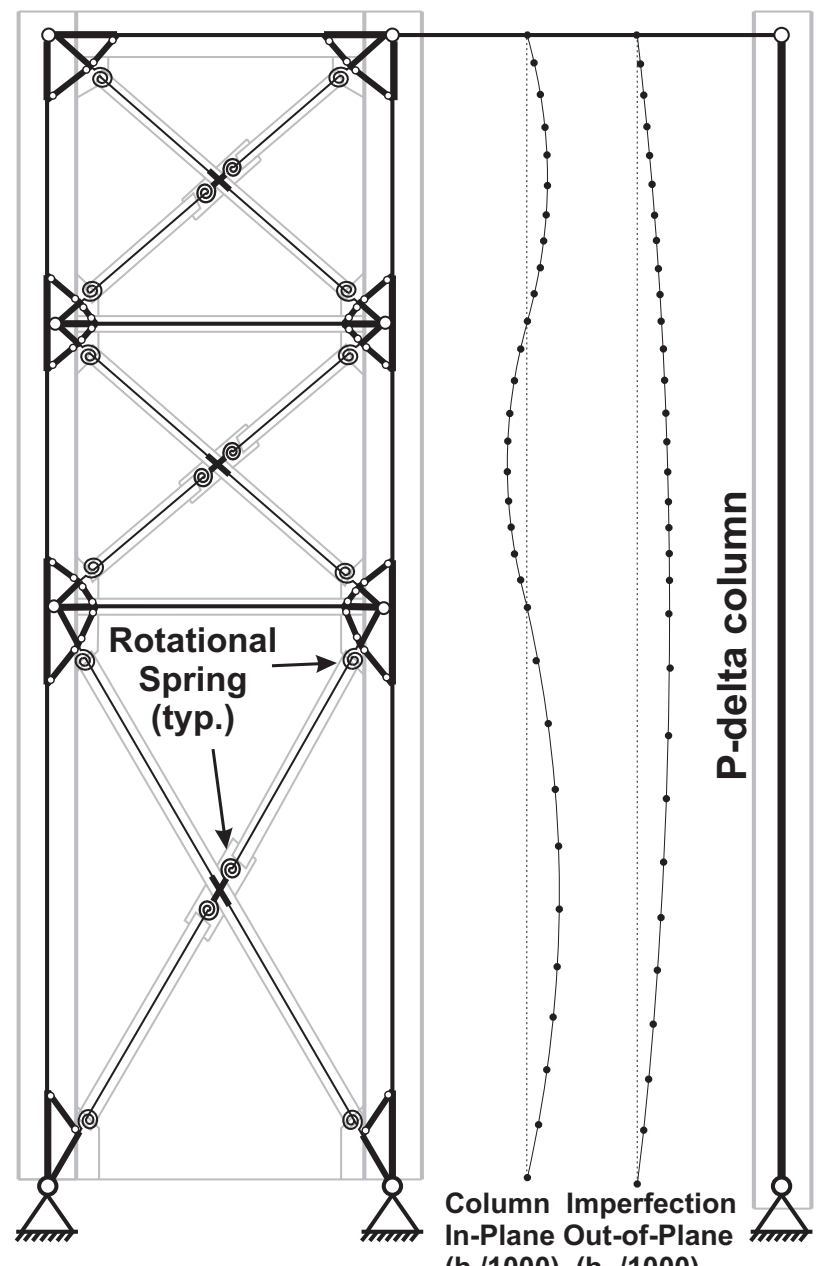

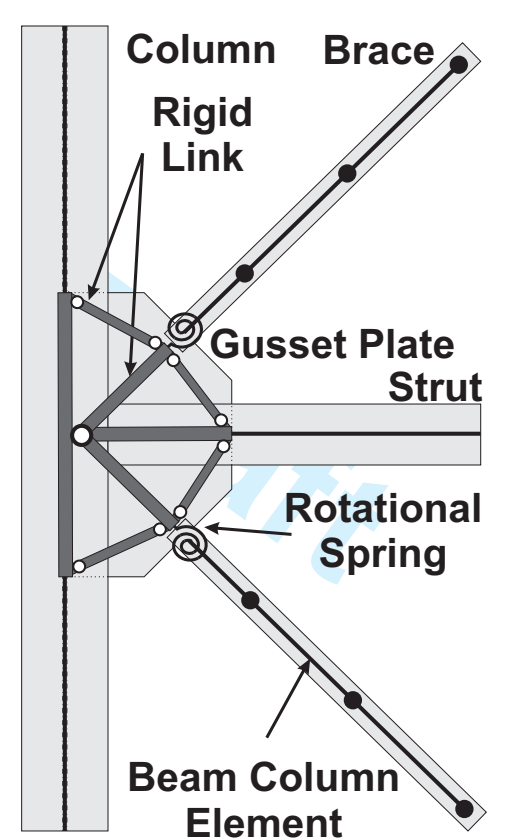

Brace Connection Model

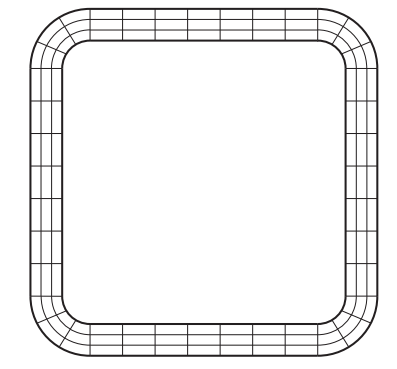

Brace Cross-Section Discretization

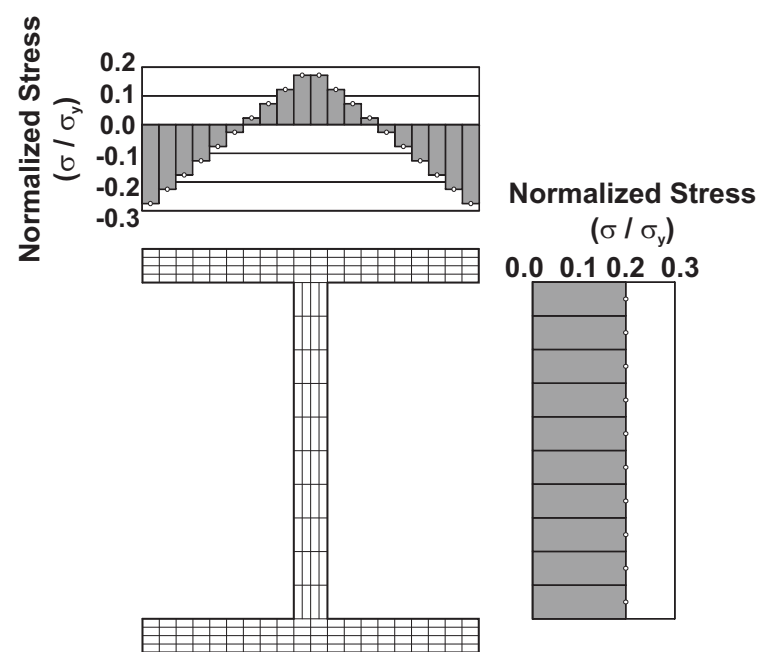

Adopted Residual Stress Pattern and Cross-Section Discretization for Columns 
a)

Braces:

Tiers 2-5: HSS89x89x4.8 Tier 1: HSS127x127x6.4

Columns:W760x257 Struts: W200×52
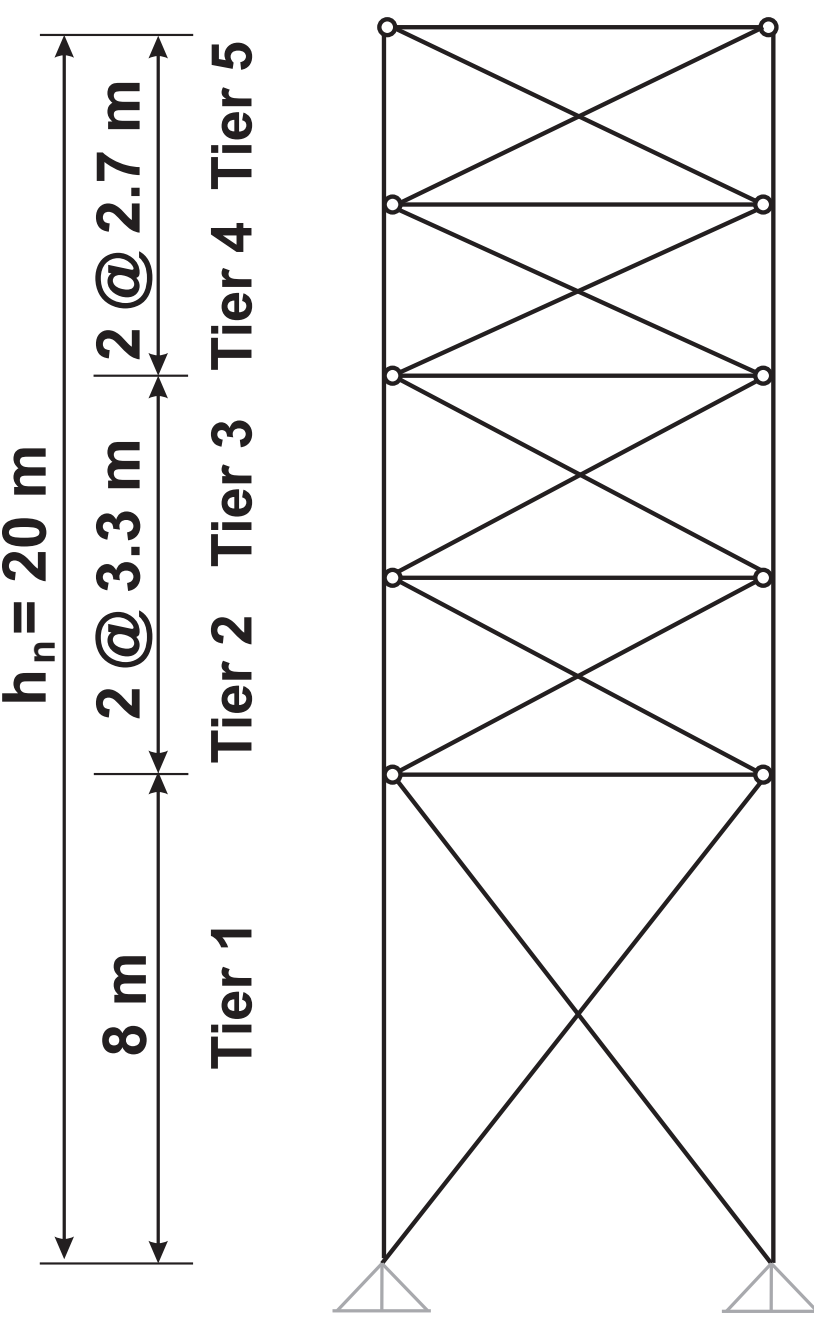

b)
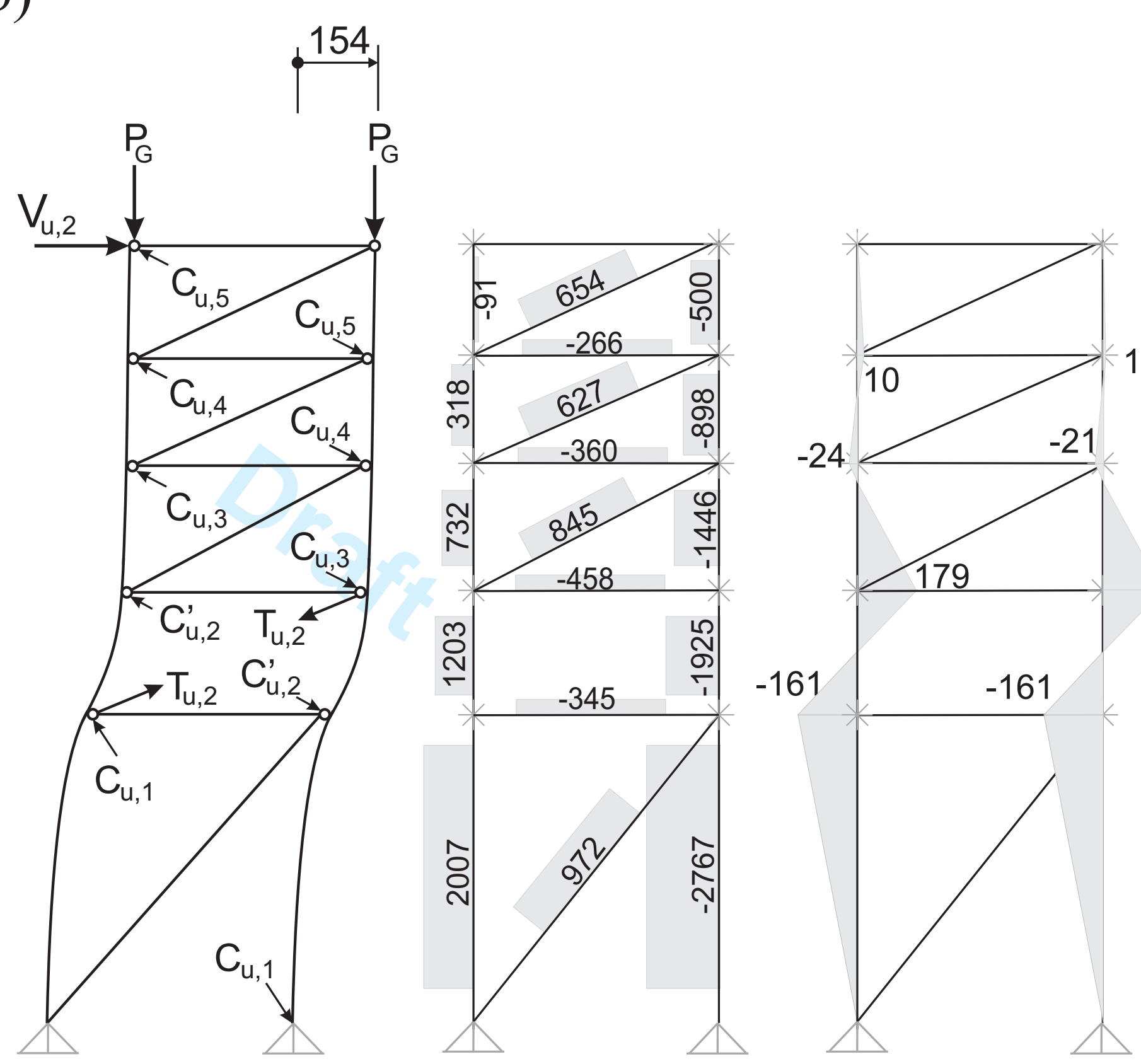

172

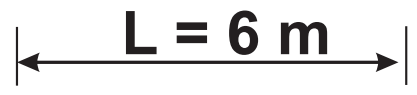

Brace Forces

$\underset{\text { e.puts }}{\mathrm{C}_{f_{s}}}-\mathrm{T}_{\mathrm{f}}$

$M_{\text {fy }}$ 
a)

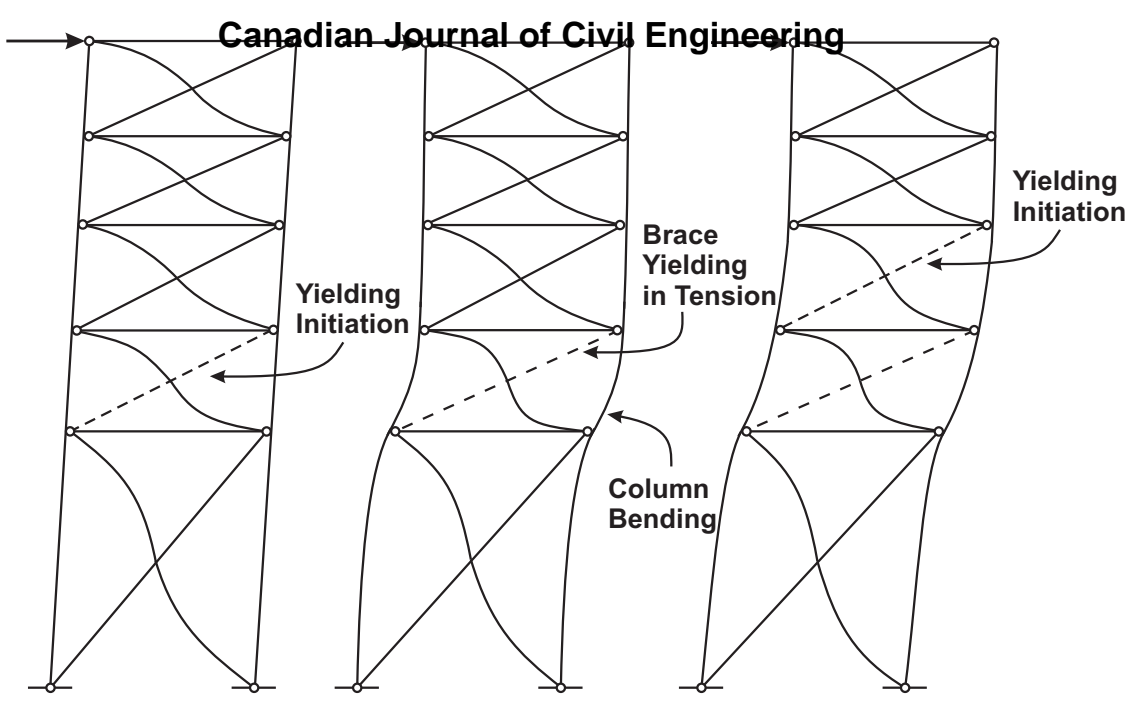

b)

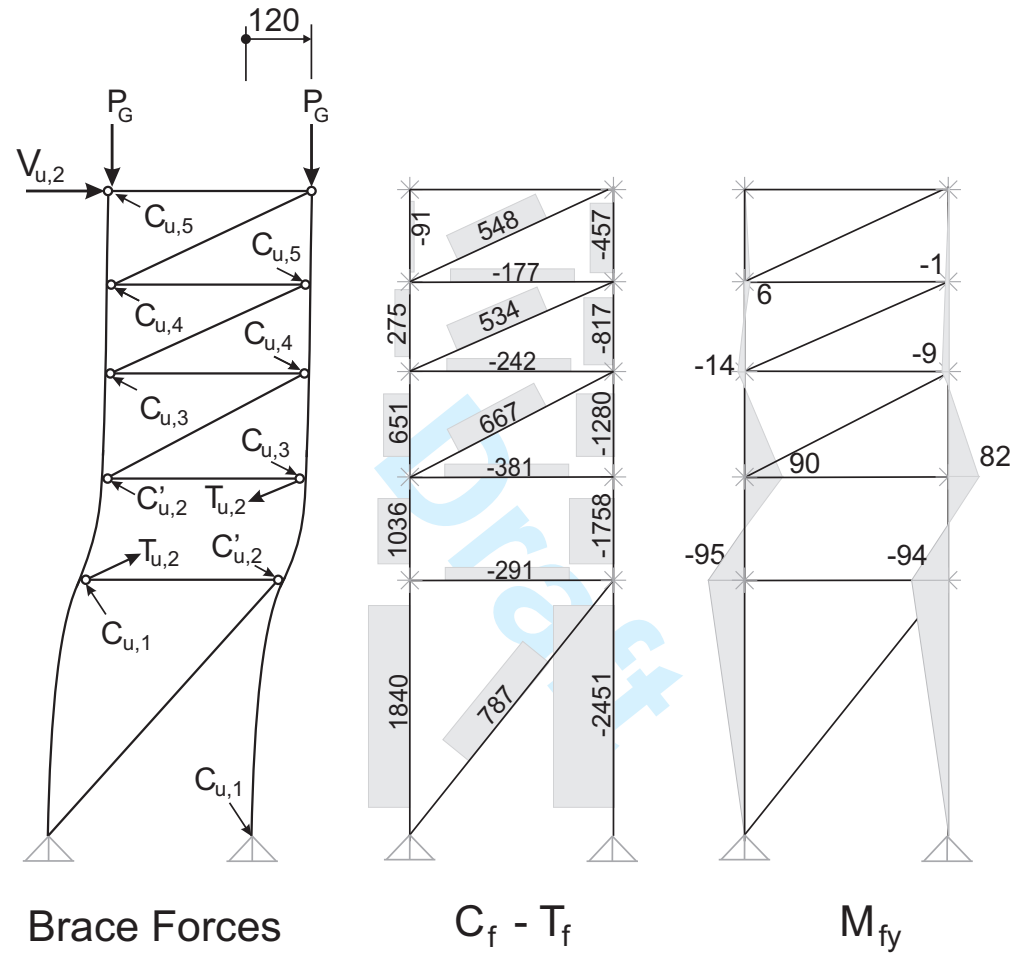

c)

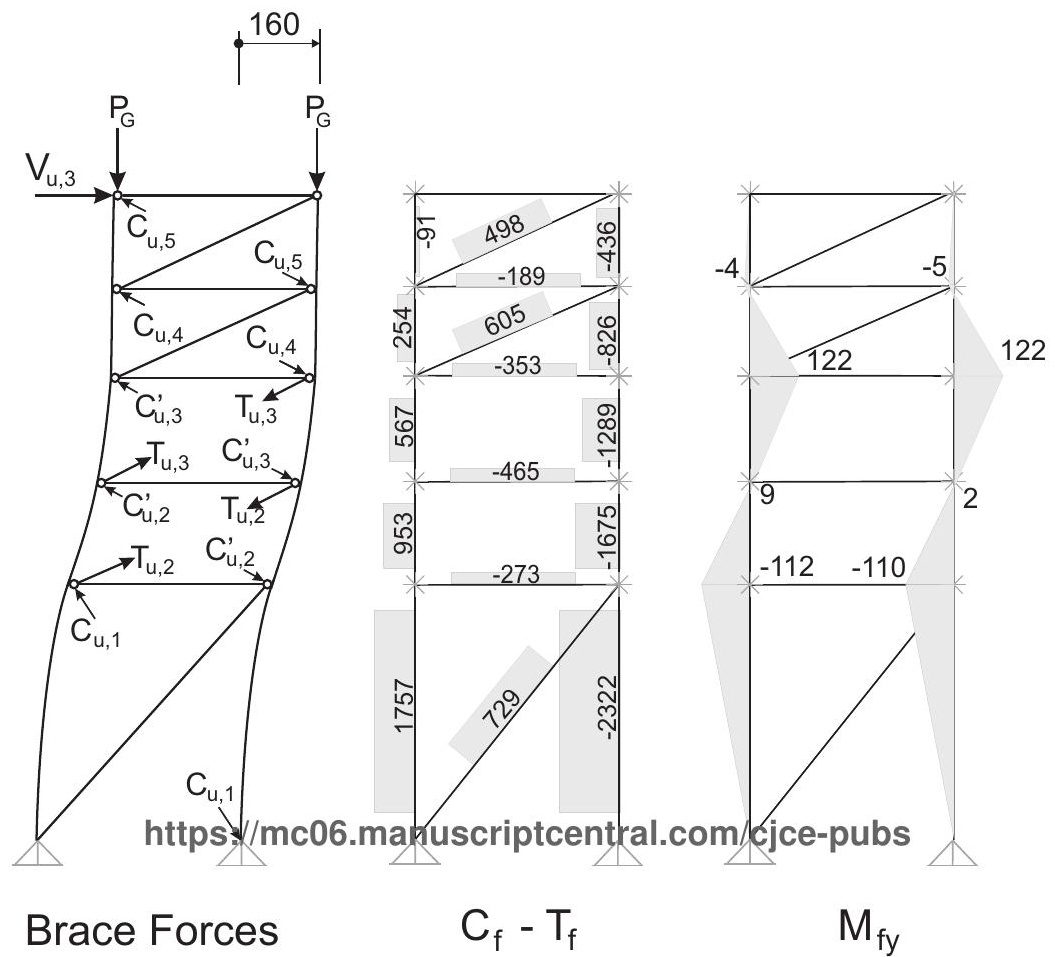

